\title{
Pattern of Blood Donors in Jos.
}

\author{
OBADIAH DAPUS DAMULAK* FMCPath. \\ SUNDAY O BOLORUNDURO** FMC ANAEST, FWACS \\ FELICIA BOMAN** $B S C S W \& A$ \\ LAMI BAKO** RNRM
}

\begin{abstract}
Correspondence to: *DR. OBADIAH DAPUS DAMULAK.
Department of Haematology and Blood Transfusion, Faculty of Medical Sciences, University of Jos, Jos.

**National Blood Transfusion Service, North Central Zonal Centre, Jos. Plateau State.

Running Title: Pattern of Blood Donors In Jos.

Work Done at: National Blood Transfusion Service, North Central Zonal Centre, Jos. Plateau State.

Running Title: Pattern of Blood Donors In Jos.
\end{abstract}

\section{SUMMARY}

Background: Blood donors are categorized into voluntary, paid, family replacement, autologous, directed and therapeutic. Superior safety has long been identified with voluntary and autologous blood donations. The setting up of the centralized blood transfusion service centre is to source blood from prospective voluntary donors among other responsibilities. AIM: To determine the types of blood donors received at the blood transfusion service and make appropriate suggestion towards transfusion safety. METHODS: We reviewed blood donor records from April 2008 to March 2010 for the pattern of blood donors received at the north central blood transfusion service centre of the National blood Transfusion Service, Jos.

Results: A total of 7286 donors were recruited in the transfusion centre and in hospital blood banks. 78.2\% were voluntary donors while $21.7 \%$ were family replacement donors all from hospital blood banks.

Conclusion: The high rate of voluntary blood donation recorded in the transfusion service is a departure from the culture of replacement donation experienced in hospital blood transfusion units. This portrays a ray of hope towards the attainment of $100 \%$ voluntary blood donation and its attendant safety. We recommend improved commitment of resources from government and donor agencies in this regard. State and local governments should establish transfusion units to collaborate with the National Blood Transfusion Service of Nigeria.

Key words: Voluntary, Replacement Donors, Transfusion Service.

\section{Introduction}

A blood donation occurs when a healthy person voluntarily has blood drawn for transfusion or preparation of medication by fractionation. ${ }^{1}$ Blood donation is largely an act of charity but a few donors do so for penury or some forms of reward earnings in developed world. ${ }^{1}$ In Nigeria, blood donation is stilled majorly for penury reason and family ties. ${ }^{2}$ There is an increasing awareness about the relationship of diseases, particularly transfusion transmissible infections and blood donation and transfusion. ${ }^{3}$ Blood can be sourced from several groups of people including paid, family replacement, autologous and voluntary non remunerated donors. It is known that the safest units of blood come from voluntary non remunerated donors, gotten from continuous sensitization, awareness creation amongst communities and the organization of indoor and or outdoor blood donation drives. ${ }^{4}$ Many developed countries of the world have since rely on voluntary blood donors to meet the transfusion requirement of their health services. ${ }^{5,6}$

Blood donation to meet the transfusion needs of a family member is responsible for majority of blood donation in Nigeria. Family replacement donors accounted for $95.7 \%$ of blood donation found in a study in Kano, North Eastern Nigeria, with voluntary blood donors contributing $4.1 \%$ and autologous $0.021 \% .^{7}$ A similar report from Maiduguri showed a rise in commercial donors from $20 \%$ to $63 \%$, autologous $1 \%$ to $9 \%$ and reduction of voluntary donors from $31 \%$ to $5 \%$ and family replacement donors declining from $49 \%$ to $23 \%{ }^{2}$ A study in South Eastern Nigeria identified a height rate of commercial blood donation, with $82.2 \%$ of the donors being males as females are culturally prohibited from blood donation. It further found donors within the age bracket of 20 to 39 
years accounting for $73.6 \%$ of all donations. ${ }^{8}$ An earlier report from Jos is not different, as only $4.5 \%$ blood donations were from females, with $81 \%$ of all the donors falling between 21 and 40 years. ${ }^{9}$ We undertook this retrospective study to evaluate the impact of the National Blood Transfusion Service of Nigeria, on blood sourcing and the implications on blood transfusion safety.

\section{Methods}

This retrospective study was carried out at the north central zonal centre of the National Blood Transfusion Service in Jos, North Central Nigeria. Records of all blood donors from April 2008 to March 2010 were reviewed for mode of donor recruitment and type of blood donation. Records included blood donors who donated to hospitals as family replacement and those who donated blood to the blood transfusion service. Blood donors of the transfusion service were categorized into voluntary (new voluntary donors, regular voluntary donors, lapsed donors) and autologous donors. Microsoft excel was applied for statistical analysis.

\section{Results}

Records of 7286 blood donors within the age range of 18 and 61 years were reviewed. There were $5260(72.20 \%)$ males and 2026(27.80\%) females who donated blood between April 2008 and March 2010. Five thousand six hundred $(78.20 \%)$ were voluntary non remunerated blood donors; of which, 3970(54.50\%) were first time donors, $1635(22.40 \%)$ were call-up regular voluntary donors, 95(1.30\%) were lapsed donors who donated twelve months or more after last donation. Family replacement donors constituted $1585(21.70 \%)$ of our donors whose blood were collected in hospitals and send to the blood transfusion service centre for testing. Table 1

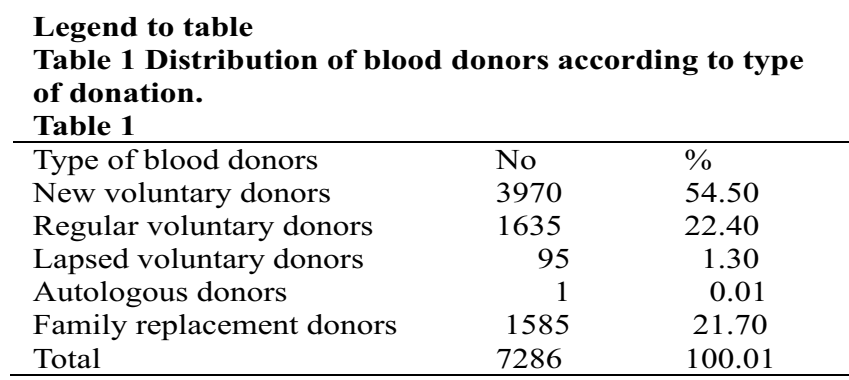

\section{Discussion}

This study identify compliance with the World Health Organization criteria on recruitment of only prospective donors between 18 and 65 years, as all the donors accepted at the NBTS centre were between 18 and 61 years. The lower limit is to take account of the increased iron requirements of adolescence while the upper limit is to take care of increased in medical conditions which might make blood donation hazardous. ${ }^{10,}{ }^{11}$ Males dominated blood donation in this study contributing $72.2 \%$. The enrollment of female donors is higher $(27.8 \%)$ in this study than reported in the North Eastern, South Eastern and North Central Nigeria. ${ }^{7,8}$ It is also higher than female blood donor enrollment in Ghana and Mali where $89.4 \%$ and $89.2 \%$ respectively are male donors. ${ }^{12,13}$ This might be due to mass awareness and sensitization talk on blood donation which could change cultural dogma that forbids females from blood donation. ${ }^{5,10}$

This study revealed a high voluntary blood donor population in the centralized blood transfusion service against the dominant family replacement and paid donation observed in hospital based transfusion service. Total voluntary donors accounted for $78.2 \%$ of blood donation, a figure far above that reported in hospital blood banks in Nigeria. ${ }^{2,7}$ This large voluntary blood donor pool consists of new or first time $(54.5 \%)$, regular or retained $(22.4 \%)$ and lapsed $(1.3 \%)$. This finding is similar to, but higher than the $63.5 \%$ voluntary blood donation reported earlier in Ghana, in both cases sensitizations were done in institutions where large pool of voluntary blood donors are expected. ${ }^{14}$ It has been reported that the rate of TTIs positive donation is lower among volunteer than replacement donors and much lower if the volunteers are regular donors. ${ }^{15,16}$ This suggest the need to intensify mass sensitizations in addition to one on one recruitment of voluntary blood donors as well as deliberate strategies toward donor retention. The advancement recorded in the communication industry via video and audio channels and telephone networks, offers a great opportunity for the attainment of $100 \%$ voluntary blood donation, increase retention and reduction in the rate of lapsed donors with ultimate improvement in transfusion safety.

Family replacement donation is still prominent $(22.7 \%)$, in our transfusion service centre as found in other parts of the African continent. ${ }^{16}$ Family replacement blood units which came through the hospital based blood banks could include blood from paid donors. This calls for an effective collaboration between staff of hospital blood banks and the transfusion service at the conversion of all family replacement, whether recipient's relatives or paid, to voluntary non remunerated blood donors. 


\section{Conclusion}

We conclude from our study that a greater proportion of our donors are from volunteers. There is the need to intensify efforts at achieving $100 \%$ voluntary blood donation to ensure transfusion safety in modern health care delivery. Resources should be committed for blood donor retention to build up the safest donor pool and eliminate family replacement donors. States and local governments should established transfusion service units to collaborate with the National Blood Transfusion Service while health care providers should encourage conversion of family replace to voluntary blood donation and reject all forms of donor remuneration.

\section{References}

1 Frequently asked question about donating blood. American Red Cross Biomedical Services. http:///www.wikipedia.org/wiki/blood 2009.

2 Ahmed SG, Ibrahim UA, Hassan AW. Adequacy and pattern of blood donation in north-eastern Nigeria. The implication for blood safety. Ann trop med parasitol, 8; 2008: 725-731.

3 Ramnik Sood. Haematology for Students and Practitioners. $5^{\text {th }}$ edition, New Delhi,Jaypyee, 2003; 358-361.

Dutta AB. In: Blood Banking and Transfusion. New Delhi; CBS, 2002; 27-52.

5 Jeffrey M. Blood procurement and screening In: Ernest B, Marshall AL, Barry SC, Thomas JK, Uri S (edds). Williams Haematology. $6^{\text {th }}$ Edition, McGrwal Hill, New York, 2002: 1871-1877.

6 Hoffbrand A V, Moss P A H, Petit J E. Essential haemetology. $5^{\text {th }}$ edition, Massachusetts, Blackwell, 2006; 337-351.

7 Kuchiya-Gwarzo A, Kwaru AH. The pattern of blood donation in Aminu Kano Teaching Hospital. J med rehab. 1;2007:35-38.

Okocha EC, Ibeh CC, Ele PU, Ibeh NC. The prevalence of malaria parasitaemia in blood donors in a Nigerian teaching hospital. J vect borne dis, 12; 2005: 21-24.

9 Egah ZD, Mamdong BM, Iya D et al. Hepatitis C virus antibodies among blood donors in jos, Nigeria. Ann Afr Med, 3; 2004: 35-37.

10 Armstrong B. Blood Donors: in International Society for Blood Transfusion. Science Series, Armstrong B, Hardwick J, Raman L, Smart E, Wilkinson R (edds). Wiley-Blackwell, 3: 2, 2008: 110-122.

11 Contreras M. Hewitt PE. Clinical blood transfusion. In: Hoffbrand AV, Mitchell SL Tuddenham GD (edds). Postgraduate Haematology. $4^{\text {th }}$ edition. London, Arnold; 2001: 182-214.
12 Adjei AA, Armah HB, Narter-Olaga EG. Seroprevalence of cytomegalovirus among some voluntary blood donors at the 37 Military Hospital; Accra, Ghana. Ghana med j, 40; 2006:99-104.

13 Tiwari BR. Karki S. Ghimire P. Yadav P. Rajkarnikar M. J Nepal Health Res. Counc. 6; 2008:93-97.

14 Owusu-ofori S. Aseno-Mensah K. Boateng P. Sarkodie F. Allain jp. Fostering repeated donations in Ghana. The Int assoc biol. 38; 2010: 47-52.

15 Diarra A. Kouriba B. Baby M. Letrere JJ. HIV, HCV HBV and Syphilis rate of positive donations among blood donors in Mali: Lower rates among voluntary blood donors. Transfus Clin biol. 16; 2009: 444-447.

16 Ampolo w. Nii-Trebi N. Ansa J etal. Infectious diseases in blood donors in Ghana. J clin microbiol. 40; 2002: 3523-3525. 